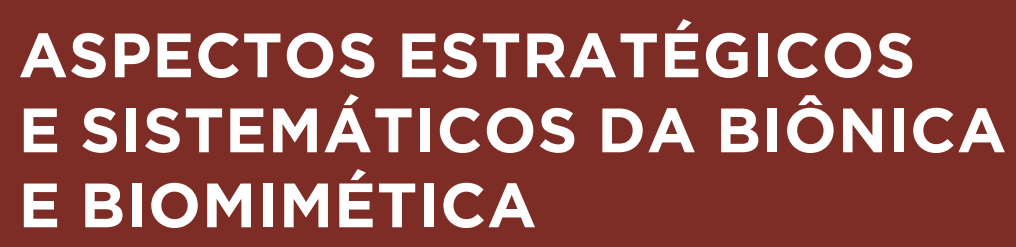




\section{SOBRE O AUTOR}

Eduardo Dias I edu@eduardodias.com.br

Lattes: http://buscatextual.cnpq.br/buscatextual/visualizacv.do?id=K4215400H2

Mestre em arquitetura pela Universidade São Judas Tadeu SP, com especialização em Design gráfico e graduação em projeto de produto pela Faculdade de Belas Artes de São Paulo. Professor no curso de Design da Universidade São Judas Tadeu-SP. Coordenador do Animalab-SP, laboratório de inovação da USJT. 


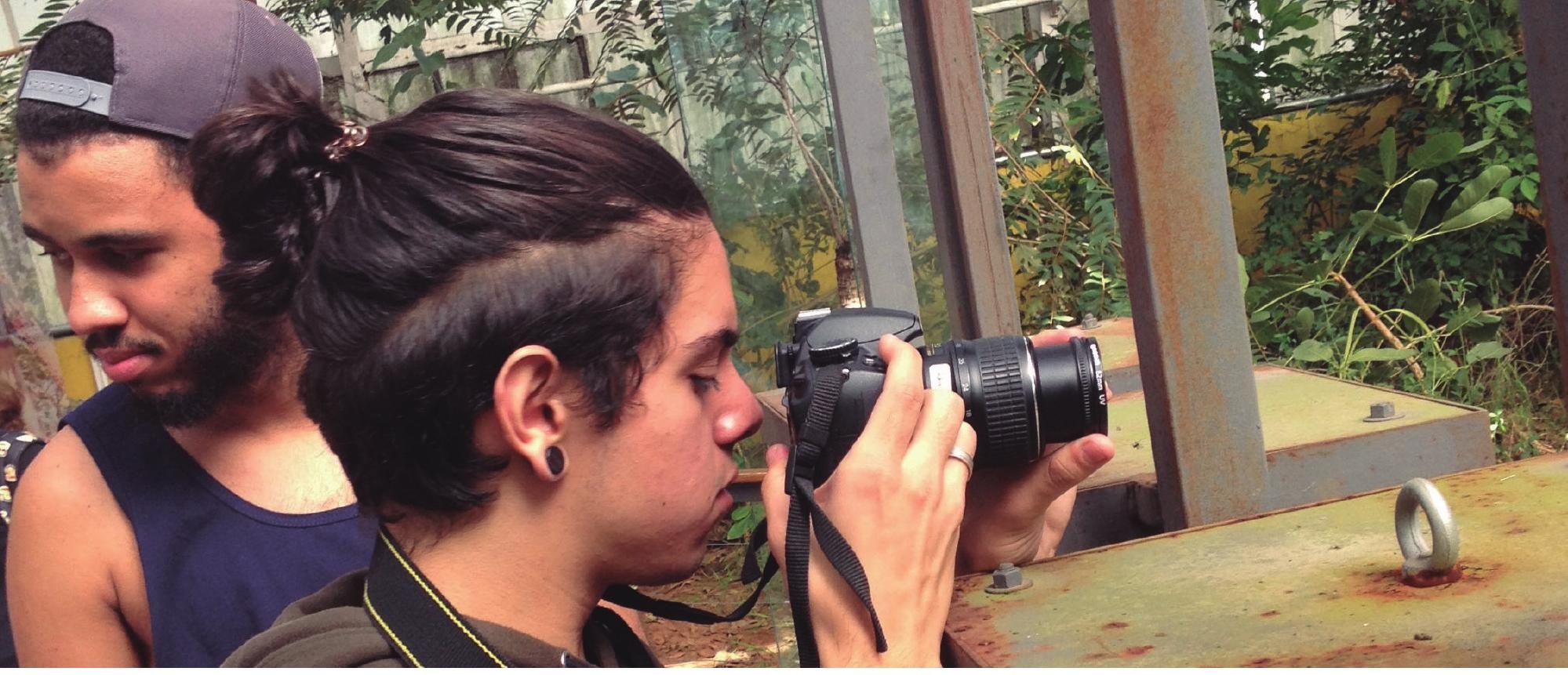

\title{
A Biomimética no Ensino do Design como Ferramenta oara o Desenvolvimento do Pensamento e da Estratégia de Projeto
}

\author{
Biomimicry in the Teaching of Design as Tool for the \\ Development of the Thinking and Design Strategy
}

Eduardo Dias*

\section{Resumo}

A utilização de metodologias baseadas na Biomimética pode ser uma estratégia interessante para incentivar a criatividade, tendo em vista que a busca de soluções na natureza provavelmente se utilizará de linhas de raciocínio em que os alunos terão de utilizar inferências e estruturar o pensamento de modo lateral ao invés de vertical.

Palavras-chave: Biomimética; Metodologia de projeto; Ensino de design.

\section{Abstract}

The use of methodologies based on Biomimicry can be an interesting strategy to encourage creativity, since the search for solutions in nature will probably be used lines of reasoning in which students will have to use inferences and structure the thinking in a lateral way rather than in a vertical way.

Keywords: Biomimicry; Project methodology; Teaching design. 
Estes são três termos que se confundem entre si por se referirem à utilização da natureza como referência na busca de soluções por problemas, apesar de que em princípio todos eles têm origem e enfoque diversos. Numa diferenciação breve, a Biomimética se refere à disciplina popularizada principalmente pela escritora estadunidense Janine Benyus à frente da Biomimicry Guild e Biomimicry 3.8, enquanto a Biônica tem seu nascimento com as pesquisas feitas nos laboratórios da NASA no início dos anos 60 pelo Major Jack Ellwood Steele. 0 termo Biodesign por sua vez é uma criação do designer Luigi Colani para definir sua ideologia projetual.

\section{INTRODUÇÃO}

Já se foi o tempo em que ao falarmos sobre Biomimética, Biônica ou Biodesign ${ }^{1}$, recebíamos de volta olhares de estranhamento, quando não de reprovação. Pior ainda quando falávamos de Luigi Colani, por exemplo, soávamos quase heréticos, o que podia nos render o exílio temporário à marginalidade dos círculos discentes e docentes. Não que hoje em dia esses termos sejam de domínio do público, mas ao menos são mais populares por conta do culto à sustentabilidade - não entremos aqui no mérito das distorções do conceito em si - e do ecologicamente correto.

Hoje as soluções fabulosas e miraculosas povoam os posts do Facebook e os incontáveis blogs pseudo-especialistas em Design e tecnologia que pululam a world wide web.

Tanto no mercado como no ambiente acadêmico, o que já foi delírio e posteriormente vanguarda hoje parece se encaminhar novamente para uma mudança de status passando a ser chamado, quem sabe, de "bola da vez".

Apesar da resistência e desconfiança iniciais, da confusão de termos e das distorções normalmente promovidas pela popularização das novas ideias, a Biomimética vem se firmando como caminho metodológico por conta da consistência e engenhosidade de suas ideias, além da perseverança e fé - sim, acho que fé cabe bem aqui - dos visionários, sonhadores, teimosos ou como preferirem se referir a todos que desde o início tem insistido na ideia de se referenciar na natureza para resolver problemas.

É essa paixão, ou fé, que tem me levado a estudar o tema desde meio da década de 1980 e adotar desde 2009 a natureza como tema central em uma das propostas na disciplina de projeto tridimensional no terceiro semestre do curso de Design da universidade em que leciono, como ferramenta para desenvolver através do exercício do projeto o raciocínio lateral, o design conceitual, a ampliação do repertório e as estratégias de projeto.

\section{POR QUE A BIOMIMÉTICA?}

Mas dentre tantas possibilidades na escolha da estratégia para resolução de problemas em projetos, por que escolher a Biomimética como estratégia?

Em primeiro lugar o fato de sermos seres biológicos e habitantes deste planeta - e assim nos encontrarmos naturalmente imersos nessa interface chamada natureza - configura uma condição que parece nos colocar numa relação extremamente amigável com todos elementos que se encontram na mesma posição, ao menos no que diz respeito à possiveis estranhamentos de aspecto sensorial. Esta familiaridade funciona como uma espécie de simpatia espontânea para com essas soluções. Quantas pessoas conhecemos que não gostam da natureza ou a acham feia?

Sabemos também que a natureza tende a manter seus sistemas em equilíbrio, gerenciando energia, matéria-prima e promovendo seus processos de seleção para a evolução. Sendo assim utilizar as estratégias extraídas da natureza 
entendendo como estas ocorrem pode ser um caminho para a manutenção do equilíbrio, o que está intimamente ligado ao conceito de sustentabilidade.

Em se falando das possibilidades para a educação, a busca de soluções na natureza provavelmente se utilizará de linhas de raciocínio em que terão de estruturar o pensamento de modo lateral ao invés de vertical.

O pensamento lógico tradicional que usamos foi criado pelos filósofos clássicos Sócrates, Platão e Aristóteles. Nele é necessário estar certo a cada passo para que se passe ao próximo. É o pensamento cartesiano, analítico, matemático, um processo finito chamado de pensamento vertical.

No pensamento lateral essa linearidade não é importante pois não se preocupa apenas com a solução do problema. Trabalha com a abstração, criatividade e imaginação explorando caminhos menos prováveis assim se configurando como um processo infinito.

Além disso, 0 ato de ter que pesquisar acaba por tornar o estudante envolvido com o assunto e o introduz a uma miríade de estímulos estético-formais aos quais ele nunca havia tido acesso ou pelos quais nunca tinha se interessado a fundo. Esse contato enriquece sobremaneira o repertório, potencializando a capacidade de criação.

O pensamento lateral muda. O pensamento vertical escolhe. [...] O pensamento vertical usa 0 sistema SIM/NÃO. O pensamento lateral não usa. [...] O pensamento vertical usa a informação pelo seu significado. O pensamento lateral usa a informação pelo seu efeito de provocar novas ideias. [...] No pensamento vertical, uma coisa deve seguir-se diretamente a outra. No pensamento lateral, pode-se dar saltos deliberados. [... O O pensamento vertical se concentra no que é relevante. O pensamento lateral acolhe de bom grado as intrusões do acaso. [...] 0 pensamento vertical se movimenta nas direções mais prováveis. O pensamento lateral explora as menos prováveis. [...] O pensamento vertical é um procedimento fechado. O pensamento lateral é aberto. (DE BONO, 1994, p.15)

Pensamento vertical

$1+1+1+1=4$

Pensamento lateral

$1+1+1+1=11 \overrightarrow{1} \vec{r}$

Por último, esse tipo de projeto se mostra propício à utilização de metodologias ativas - afinal a cooperação é usual na natureza - o que pode incentivar engajamento dos alunos e comprometimento em relação aos objetivos pretendidos pelo grupo.

\section{A PROPOSTA}

Após uma aula teórica sobre como o homem vem interagindo coma a natureza através do tempo ${ }^{2}$ e sobre a disciplina Biomimética, os alunos receberam um briefing com as seguintes orientações para o projeto:

Os alunos deverão formar grupos de até 4 integrantes e selecionar um organismo vivo, estrutura ou sistema da natureza e estuda-lo através de pesquisa bibliográfica, vídeos e visitas em campo. Todo material recolhido será

\footnotetext{
2 RIBEIRO, Carlos Eduardo Dias. A natureza no processo de design e no desenvolvimento do projeto. São Paulo: SENAISP Editora, 2014.
} 


\section{${ }^{3}$ Ao ter que traduzir a informação para as análises gráficas o aluno estabelece uma relação de raciocínio e de compreensão da estrutura mais profunda a fim de poder representa- la de modo mais eficiente. Pontos que antes poderiam passar despercebidos devem ser observados com mais atenção por conta dessa representação.}

\section{${ }^{4}$ A caixa preta é um figura que substitui a informação que não se tem em um projeto. Pode se referir à uma tecnologia que ainda não se domina ou mesmo a dados que não se possui.}
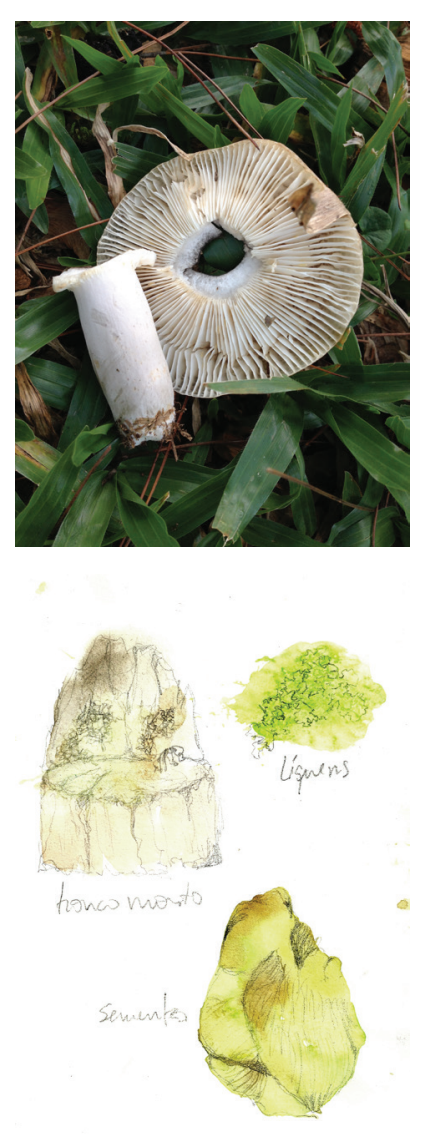

Figura 1: Registro dos objetos de estudo por meio de aquarelas transformado em análises gráficas ${ }^{3}$ a fim de elaborar estratégias a serem aplicadas para resolver algum tipo de problema através de um produto que pode ser conceitual - com possibilidade do recurso da "caixa preta"4 - ou exequível.

\section{Objetivos}

- Conscientizar da necessidade de uso de planejamento do projeto mesmo que sem seguir uma metodologia específica e declarada.

- Ampliar repertório e desenvolver senso de estética e criatividade.

- Propor inovação através do estudo estético-morfológico da natureza.

- Desenvolver a capacidade de criar configurações tridimensionais.

- Aprimorar os instrumentos de pesquisa e o empirismo.

- Demonstrar a importância do design conceitual.

- Introduzir os conceitos do biomimetismo para uso no desenvolvimento do projeto como alternativa metodológica.

\section{Metodologia}

O trabalho seguirá a seguinte ordem de ações:

- Seleção do objeto de estudo.

- Pesquisa em relação a este objeto de estudo recolhendo dados através de pesquisa bibliográfica e pesquisa de campo.

- Análises gráficas segundo as categorias descritas a seguir:

a) Análise formal: diz respeito à estrutura formal externa do objeto de estudo;

b) Análise estrutural: diz respeito à análise de estruturas responsáveis por funções relacionadas à física do objeto dando ênfase ao aspecto estrutural, como é constituído, se possui camadas ou elementos que proporcionem resistência física e estabilidade, por exemplo.

c) Análise visual: se refere à parte estética, texturas, cores, dimensões, proporções;

d) Análise de movimentos e funcional: diz respeito às estruturas que exerçam funções mecânicas e de funcionamento do sistema biológico;

e) Análise desconstrutiva: busca no objeto de estudo elementos estéticoformais que possam gerar informações simbólicas que relacionem o produto com significados culturais, espirituais, religiosos, políticos, socioeconômicos etc. É a busca de parte da referência ou informações reinterpretadas que possam dar origem a novas informações visuais e semânticas;

- 4. Conceituação: definição da estratégia através dos conceitos recolhidos a serem utilizados.

- 5. Concepção: criação do produto. 
- 6. Prototipagem;

- 7. Apresentação.

\section{DESENVOLVIMENTO}

Em poder destas informações os alunos trabalharam em grupos iniciando por pesquisas na internet, canais especializados na TV por assinatura, na biblioteca da universidade, em parques, no zoológico de São Paulo e no Jardim Botânico de São Paulo.

A princípio os grupos se mostraram razoavelmente perdidos dada a novidade da proposta, a liberdade de ação e a enorme variedade de possibilidades de objetos para estudo. Este é um momento em que o professor teve que atuar como mentor e auxiliar no gerenciamento das fases do projeto tomando cuidado para não interferir demasiadamente.

Dois procedimentos foram utilizados nessa fase inicial. 0 mais comum foi, partindo de um objeto, ver quais conceitos poderiam se extraídos e quais problemas esses conceitos poderiam resolver. Um segundo caminho - menos usual - foi partir de um problema e buscar estruturas que pudessem trazer respostas.

Os trabalhos se iniciaram com a recolha de dados pelos alunos e consequentemente pelo maravilhamento perante a riqueza do mundo natural. O nosso modo de vida atual por vezes não permite que esse contato se dê da forma que ocorria em anos passados e até em outras gerações. Nosso relacionamento com o mundo natural cada vez mais se faz por meio de interfaces eletrônicas e virtuais e a experiência da volta desse contato mais próximo não acontece de impunemente.

0 passo seguinte foi a passagem dessas informações para pranchas gráficas em forma de análises. Aqui temos sempre desde infográficos, textos, esquemas e mesmo afloramentos artísticos na forma de belas aquarelas e desenhos com marcadores e lápis de cor. A atmosfera descontraída colabora para a absorção sem resistência dos conhecimentos e o empoderamento do aluno como agente difusor de tudo aquilo que passa a saber.

Durante esse processo é normal que os grupos troquem informações e isso aumenta ainda mais o intercâmbio sobre os diferentes processos utilizados pelos grupos para obter e processar as informações.

Com os dados recolhidos traduzidos na forma de pranchas gráficas contendo as análises sugeridas os grupos escolheram as estratégias e conceitos a serem utilizados e propuseram soluções, que puderam ser prototipada ou simplesmente apresentadas em pranchas.

\section{RESULTADOS}

As soluções e posturas dos grupos foram as mais diversas. Desde conservadoras e retraídas, onde os alunos não conseguiam se desvencilhar do pensamento raso ou do estado da arte, até o completo "desvario" de ideias 


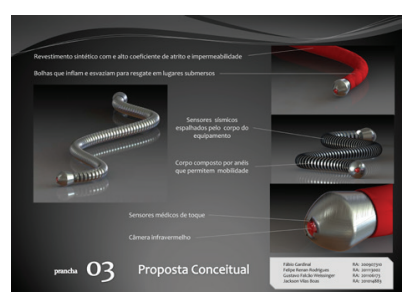

Figura 3: Solução conceitual proposta pelos alunos Fábio Gardinal, Felipe Rodrigues, Gustavo Weissinger e Jackson Vilas Boas sem cabimento - mesmo com a possibilidade de utilização de caixa preta. De qualquer modo, como o objetivo principal era o exercício intelectual, as ideias absurdas não chegaram a ser um problema.

A grande recompensa tem sido perceber que o modo de pensar as soluções de projeto tem mudado entre estes alunos e que este comportamento foi assimilado e é carregado por eles, o que pode ser comprovado pela "contaminação" de soluções biomiméticas que têm se apresentado em disciplinas de outros semestres e até nos trabalhos finais de graduação em nossa universidade.

Além disso, não são raros os relatos de alunos que se sentiram pressionados - de um modo bom - até o seu limite e dos que disseram ser esse tipo de experiência que esperavam quando buscaram o curso de Design.

\section{CONCLUSÃO}

Não há dúvidas de que todos os alunos nestes nove anos de execução da proposta tenham alcançado ao menos quatro dos sete objetivos listados no briefing. Mesmo aqueles com maiores dificuldades ou menos interesse no assunto reconhecem a importância da proposta e o valor que esta agrega à sua educação.

0 projeto tem sido revisado e atualizado ano a ano devido às mudanças na tecnologia - o movimento maker deu grande impulso no que diz respeito às possibilidades de prototipagem -, o perfil dos estudantes e na consciência ecológica, ética e social da população.

\section{REFERÊNCIAS}

ARRUDA, Amilton José Vieira. Bionic basic: verso um nuovo modello di ricerca progettuale. Tese (Doutorado em Desenho Industrial e Comunicação Multimidia) - Politecnico di Milano, Milão, 2002 BENYUS, Janine M. Biomimicry: innovation inspird by nature. New York: Harper Perennial, 1997.

DE BONO, Edward. O pensamento lateral na administração. São Paulo, Saraiva, 1994.

HSUAN-NA, Tai. Sementes do cerrado e design contemporâneo. Goiânia: Editora da UCG, 2002.

HUNT, Lenne; CHALMERS, Denise. University teaching in focus: a learning-centered approach. Austrália: Acer Press, 2012.

RIBEIRO, Carlos Eduardo Dias. A natureza no processo de design e no desenvolvimento do projeto. São Paulo, Senai, 2014

VASCONCELOS, Augusto Carlos de. Estruturas da natureza: um estudo da interface entre biologia e engenharia. São Paulo, Studio Nobel, 2000 